\title{
BUSINESS PERFORMANCE AND FINANCIAL HEALTH ASSESSMENT THROUGH ARTIFICIAL INTELLIGENCE
}

\author{
Tomas Krulicky ${ }^{1, a}$ and Jakub Horak ${ }^{1, b, *}$ \\ ${ }^{1}$ Institute of Technology and Business in České Budějovice, School of Expertness and Valuation, \\ Okružní 517/10, 37001 České Budějovice, Czech Republic \\ akrulicky@mail.vstecb.cz, bhorak@mail.vstecb.cz \\ *Corresponding author
}

Cite as: Krulicky, T., Horak, J. (2021). Business performance and financial health assessment through artificial intelligence, Ekonomicko-manazerske spektrum, 15(2), 38-51.

Available at: dx.doi.org/10.26552/ems.2021.2.38-51

Recieved: 11 August 2021; Received in revised form: 28 October 2021; Accepted: 15 November 2021; Available online: 30 December 2021

\begin{abstract}
:
Research background: Globalisation and the development of technology introduce new requirements for effective business management. Every business must constantly adapt to the environment, analyse and know its competitors and its customers' requirements, and meet other stakeholders' commitments. An unsuccessful business will go into liquidation. The intention of any business should be not only to avoid this situation, but to thrive and prosper and create value for its shareholders.

Purpose of the paper: The aim of this study is to propose an appropriate tool for cluster analysis and determine the ability of a business to survive a potential financial distress.

Methods: Details from financial statements of construction companies operating in the period 2015-2019 in the Czech Republic are analysed. Attention is mainly directed to items that represent the capital and asset structures of a company, liquid assets, and the ability to generate sales and profit. Artificial neural networks in the form of Kohonen networks are used for the purpose of cluster analysis. Financial analysis is used to examine the underlying dataset as well as for a detailed analysis of selected clusters, i.e. the contribution margin and ratio indicators.

Findings \& Value added: The basic analysis clearly shows that companies in liquidation attempt to reduce the value of inventories and engage additional foreign capital with a view to survival, while there is a certain solidarity between companies' key persons. Cluster analysis using Kohonen networks is quite successful. The present methodology and approach can still be applied to the design of an enterprise decision support tool. Further research may study whether the representation of businesses in the different clusters will change over time, or whether the development of the construction industry can indeed be predicted based on an analysis of the leaders.
\end{abstract}

Keywords: business performance, corporate finance, cluster analysis, artificial neural networks, financial analysis

JEL Classification: C38, G17, L25 


\section{Introduction}

Through economic modelling, vulnerable sectors are identified and a key message communicated: in no case can the risk of serious impact be fully eliminated; however, in most cases, it can be significantly reduced. While infrastructure may be vulnerable to natural disasters and risks that are difficult to predict, it is all about technical solutions and the capacity for and speed of response to economic events. Prevention should be based on improved analysis and models that can indicate a potential crisis in advance. Faulty financial engineering, a stubborn persistence with a set financial policy, a focus on short-term profit, betting on poor technology, and a rush to consolidate are extremely dangerous from a financial viewpoint. Due to intertwining markets and their extreme dynamics, any crash is followed by an amplified reaction that is global in nature for larger companies, and can definitively 'sink' a troubled company (Carrol and Mui, 2008). It was these scholars who pointed out, just before the financial crisis itself, that it had been enough for managers and owners or investors of such businesses to look more into the past and use methods that could detect future problems.

Economic forecasting of business development is extremely important not only for the management and owners, but also for countries, as represented by governments. Furthermore, as Sovacool et al. (2017) point out, even if extensive lessons were learned in the past, further similar cases will be extremely difficult to avoid. Among other things, this is because of the phenomenon of the future technology boom which, in the cases of, for example, electromobility or e-business, is accompanied by an unexpectedly high enthusiasm of investors willing to ignore signals about the financial health of some businesses for quite a long time. From the viewpoint of management, investors, regulators, and even countries, the most effective financial forecasting is essential. The risk of failure can never be fully eliminated; however, the question of the likelihood of surviving any financial distress is the key to all of the above. Economic research, which must be based on current scientific sources as well as practice, is then used to address this issue. There is a range of methods, models, and their combinations available. Financial decisions are often based on classification models that are used to assign a set of observations to predefined groups. Diverse data classification models have been developed to predict an organisation's financial crisis, while issues such as the selection of appropriate variables (features) that are relevant to the problems at hand have been intensively addressed by current research (Uthayakumar et al., 2021).

In the past few decades, academic research focused on bankruptcy prediction using traditional statistical techniques (e.g. discriminant analysis and logistic regression), followed in recent years by early artificial intelligence models (especially artificial neural networks). Then, in the first decade of the 21st century, the models further evolved to the use of advanced neural network models and machine learning. Due to this development, the models' performance can be increased by up to $10 \%$ compared to previous models (Barboza et al., 2017), while their performance continues to grow due to continuous technological advances and the use of specialised techniques and software. According to Lehtinen (2007), the intensifying development trends, and faster and deeper transformations are quite typical of the current market environment; thus, businesses must constantly adapt to them. This situation has resulted in our being ever closer to an advanced economy and the associated hypercompetition. Since competition is on a constant rise, businesses are required to focus on their performance and, above all, their future development. Andekina and Rakhmetova (2013) believe that analysing the development of economic conditions, examining the impact of factors on the process of economic phenomena, overall assessment, and the prediction of potential risks or future development of a firm are the essential activities that can affect the 
operation of a business in the current business environment, especially its further development.

The aim of this study is to propose an appropriate tool for cluster analysis and determine the ability of a business to survive potential financial distress.

To achieve the purpose and objective of the study, and considering the nature of the methods used, three research questions are formulated:

RQ1: Is cluster analysis an appropriate tool for identifying companies that face bankruptcy?

RQ2: Can businesses be categorised by common characteristics into groups of successful and unsuccessful businesses?

RQ3: Can cluster analysis be used to identify key indicators that feature failing businesses?

\section{Literature review}

Generally, the main prerequisite for the long-term existence of a business and its success, according to Nenadál et al. (2011), is primarily the fact that they can constantly transform and adapt to the prevailing market needs. The current market, according to Kenny (2012), is characterised by the elimination of business barriers and technological growth. It provides businesses with many opportunities for development; however, it simultaneously presents many new threats and risks. Thus, it is absolutely crucial for all stakeholders in the current market environment to know the performance of their company and to be able to predict its future situation and value, thus not only providing managers with the necessary information for decision making, but also planning the future use of resources and other actions directly related to the management of the company (Le et al., 2020).

One of the most significant current trends related to business evaluation and performance is that sustainability trends are intertwined. Although it may seem that non-financial and financial reporting are only indirectly linked, recent actions by multinational groups, countries, or financial institutions challenge this view. Sustainability is now the fundamental condition for the survival of businesses in many industries, while others are affected by, for example, significantly rising costs of capital or increasing levels of regulation. This is also exemplified by the current research that has been increasingly focused on sustainability over the last decade. The efforts to compile non-financial reporting, often presented in the form of environmental, social, and corporate governance (ESG), and traditional corporate performance indicators have led to numerous studies and analyses. The studies are mainly focused on the principle of mutual conditionality, where business as such is already directly linked to sustainability in many industries; additionally, they attempt to explain the impact of compliance, or the corporate risks of rejection, where, for example, according to Nirin et al. (2021), there is an increased risk of financial problems and the associated termination of business, or at least failure to meet the set goals. Thus, businesses currently have no choice but to strive to facilitate the emerging socio-technological paradigm and face the challenge of how to gain competitive advantages from this process, or adapt their goals and activities most effectively (Gupta et al., 2020).

While the trend towards sustainability has been the subject of interest in intense economic research for approximately two decades, the COVID-19 pandemic came as a considerable shock - a 'black swan' (Verma and Gustafsson, 2020). According to these authors, in less than a year, almost a tenth of economic analyses and studies have been dedicated to the impact of the pandemic. As their meta-analysis of 207 cited outputs from Scopus and Web of Science shows, the authors have thus far focused on four main research topics of 18 sub-topics, with 
the impact of such a global threat on business performance being one of the dominant areas of interest. It can therefore be concluded that performance analysis and the prediction of the future development of a firm are among the most important tools that a firm can hardly do without.

Currently, there is a wide range of methods available which can be used to measure business performance. Their application depends on the prevailing market situation, as performance measures evolve as the market environment develops (Narkunien and Ulbinaite, 2018). Malichová et al. (2017) agree and add to this statement that there has been a significant shift in the indicators that can measure business performance. They further observe that assessment tools are essential for a business as they cannot only reveal strengths, weaknesses, threats, and opportunities, but can also determine the success of the business in the market compared to its competitors (Linna and Jaakkola, 2010).

The complex approaches include Balanced Scorecard, Model Excelence, and Six Sigma. Machine learning and neural networks comprise a separate group of tools for measuring business performance: a dynamic environment with many uncertainties; new forms of business and not only the availability, but above all, the need for processing large volumes of data; adequate computing power and proven software tools. All the above currently make the methods of artificial neural networks among the most effective tools for the evaluation and predictive modelling of business development. Especially for predicting financial distress, deep learning techniques using LSTM or recurrent networks work better than traditional techniques using mainly static time series (Halim et al., 2021). The original purpose of using machine learning in economic models was primarily to eliminate some of the original problems associated with statistical models, especially data stationarity. However, these new methods, which are mainly based on the use of artificial neural networks, have evolved to a point where, according to Abdou et al. (2017), they outperform the original statistical models.

Financial analysis and artificial neural networks, i.e. Kohonen networks, will be the methods used in this study. Their application has the potential to examine the relevant aspects of businesses / firms operating in the transport sector in the Czech Republic.

\section{Data and methods}

A dataset was created to include complete financial statement data, i.e. balance sheets and profit and loss statements of companies which operated in the construction industry in the Czech Republic in the period 2015-2019. These are businesses whose predominant activity / objects are classified in Section F of the CZ NACE sectoral classification of economic activities. The set of businesses is generated from the CRIBIS database of CRIF - Czech Credit Bureau. The details of the construction companies (131,950 records in total) will be provided in a spreadsheet file using MS Excel.

Cluster analysis will include items representing the capital structure, asset structure, liquid assets, and the ability to generate profit and sales.

Financial analysis will be based on details from the financial statements of construction companies that operated in the Czech Republic in the period 2015-2019. Details concerning the property (assets) and capital (liabilities) as of the end of the accounting period and the profit and loss statement will be used. The financial characteristics of an average construction company will be determined by averaging the values indicated for the individual items of all reference enterprises per given year. Following the appropriate adjustment of the data, the file will be cleaned to eliminate nonsense or missing values. This assumes that the frequency of 
outliers will not significantly affect the result (mainly due to the use of a large volume of data).

In terms of methodology, the profitability, debt, liquidity and activity ratios will be analysed first. Consequently, the use of foreign capital, a company's assets, receivables, and liabilities will be analysed. All this will be done for the input dataset to examine the underlying dataset. Thus, the health of the construction sector in the Czech Republic will be determined.

Similarly, financial analysis will be conducted to analyse selected clusters of active businesses, companies in liquidation, and overall. This analysis will follow cluster analysis using Kohonen networks. Thus, the status and differences in each major cluster will be identified.

The available dataset will first be subject to cluster analysis using Kohonen networks. The Statistica software of Tibco version 13 will be used for cluster analysis. The data mining module will be applied, and Neural Networks will be used as a specific tool. The file will be divided into three parts:

1. A training dataset, representing $70 \%$ of the companies in the dataset. A Kohonen network will be built on this dataset.

2. A test dataset, representing $15 \%$ of the companies in the original set. This dataset will be used to verify the parameters of the Kohonen network which was created.

3. A validation dataset, representing $15 \%$ of the companies in the dataset. This dataset will also be used to validate the Kohonen network which was created, i.e. whether it can be used.

The analysis will mainly examine the average values of the individual clusters. This will determine the most successful clusters of companies in the construction industry.

The topological length and width of the Kohonen map will be set to 10 . The number of repeated calculations, i.e. iterations, will be set to 10,000 . However, the level of error makes the difference: if the Kohonen network parameters do not improve with each successive iteration, the training will be finished before the 10,000th iteration is performed. If the network parameters are still improving at the 10,000th iteration, the whole process will be repeated, and the required iterations will be set higher to ensure that the result obtained is the best possible. The speed of learning will be set to 0.1 at the beginning and 0.02 at the end.

The results, i.e. the breakdown of the individual companies into clusters (there will be 100 of them), will be imported back into the Excel spreadsheet file. Subsequently, the selected clusters will be analysed for absolute and selected ratio indicators and the results will be interpreted. It will be determined whether we will look for clusters that show extremely high absolute values of the selected variables or, alternatively, whether we will look for clusters that, on average, show the highest values. At this point, the question will need to be answered as to how we should roughly understand the industry leader. A number of variables can be selected. The values that will be part of the financial analysis of the underlying dataset (profitability, debt, liquidity, or activity ratios; foreign capital indicators; a company's assets indicators; receivables ratios; or ratios characterising a company's liabilities) will be included in those variables.

The analysis will mainly examine the average values of the individual clusters. This will determine the most successful clusters of companies in the construction industry.

The whole analysis will be performed such that a variable (classification criterion) will also be included to divide businesses into active (successful) and liquidation (unsuccessful). The aim will be to establish whether enterprises cluster according to the criteria into 'successful' or 'unsuccessful', whether unsuccessful enterprises are significantly represented 
in specific clusters, and whether successful enterprises are significantly represented in other specific clusters. If there is a situation in which unsuccessful enterprises cluster and significantly dominate in specific clusters, the financial analysis will allow us to deduce which specific variables, and at what intervals, have an impact on whether a firm will be successful or unsuccessful.

\section{Results}

The adjusted input data forming the underlying dataset were examined using the selected tools of financial analysis. In aggregate, 3,670 companies, of which 50\% were active and 50\% were in liquidation, were analysed.

\subsection{Cluster Analysis - Kohonen Networks}

Following the adopted methodology, the adjusted dataset was subject to cluster analysis using Kohonen networks. We will attempt to determine whether companies cluster according to the criteria of 'successful' and 'unsuccessful'. In other words, whether successful companies are significantly represented in specific clusters, and the same with unsuccessful ones. In total, companies are distributed in 100 clusters according to a $10 \times 10$ grid. Finally, after all data adjustments, a total of 3,670 companies entered the calculation, of which 1,835 were active and 1,835 were in liquidation (i.e. $50 \%$ by 50\%). Table 1 shows the frequencies of companies in each cluster.

Table 1: Enterprise frequency table

\begin{tabular}{llllllllllll}
\hline \multicolumn{7}{c}{ Network: 1.SOFM 19-100 } \\
\multicolumn{2}{l}{ Samples: Training, Test, Validation }
\end{tabular}

Source: Own production

The trained network is a SOFM 19-100 network, while the calculation includes 19 items from the financial statements, and the enterprises are divided into 100 clusters. It is obvious from the table that the largest is Cluster $(1,10)$, which contains a total of 1,053 enterprises. The second largest is Cluster $(7,10)$, and the third Cluster $(10,10)$. Generally, clusters in the tenth position in terms of column are more significant. There are markedly fewer enterprises represented in the other clusters. A quite large group of clusters (12 in total) contains no enterprises.

A vast majority of companies in liquidation are contained in the aforementioned cluster, (1, 10), where the result is very good as the largest cluster comprises only companies in 
liquidation. This indicates a very good ability of the generated Kohonen network to classify companies in clusters according to their characteristics.

The clusters contain at least $80 \%$ of companies in liquidation. Therefore, these groups can still be characterised as clusters which present a bankruptcy zone. The largest cluster in this group is Cluster $(3,7)$, which contains a total of 43 companies, of which 37 are in liquidation and only 6 are active.

The clusters that include such a large number of active companies and those in liquidation that their portion of companies in liquidation is large compared to that of active enterprises belong to the so-called grey zone. Businesses included in this category do not show signs of bankruptcy; however, their susceptibility to problems is significant, and the companies need to take actions to avoid possible bankruptcy. The goal of these companies is, of course, to move out of the grey zone and into the zone of creditworthy companies. The table shows that, in terms of numbers, Cluster $(5,9)$, which contains 62 companies, is the largest, with exactly half falling within the group of active companies and the other half ranked as companies in liquidation.

A total of 7 clusters only comprise active companies; these clusters are less populated, and contain only between 1 and 8 companies. Thus, the larger clusters include both active companies and those in liquidation (except for the significantly represented clusters that only contain companies in liquidation). This fact suggests that the generated Kohonen network can classify companies in liquidation quite precisely.

The largest cluster in terms of the credit zone is Cluster $(7,10)$. It contains 427 companies, of which only $4.22 \%$ are in liquidation. The second largest is Cluster (10, 10), with 399 companies, of which only $5.51 \%$ are in liquidation. Some of the other clusters include more companies in liquidation, with the proportion of these companies being above $30 \%$.

The situation regarding the number of active companies in the clusters is illustrated in Figure 1.

Figure 1: Active enterprises in clusters

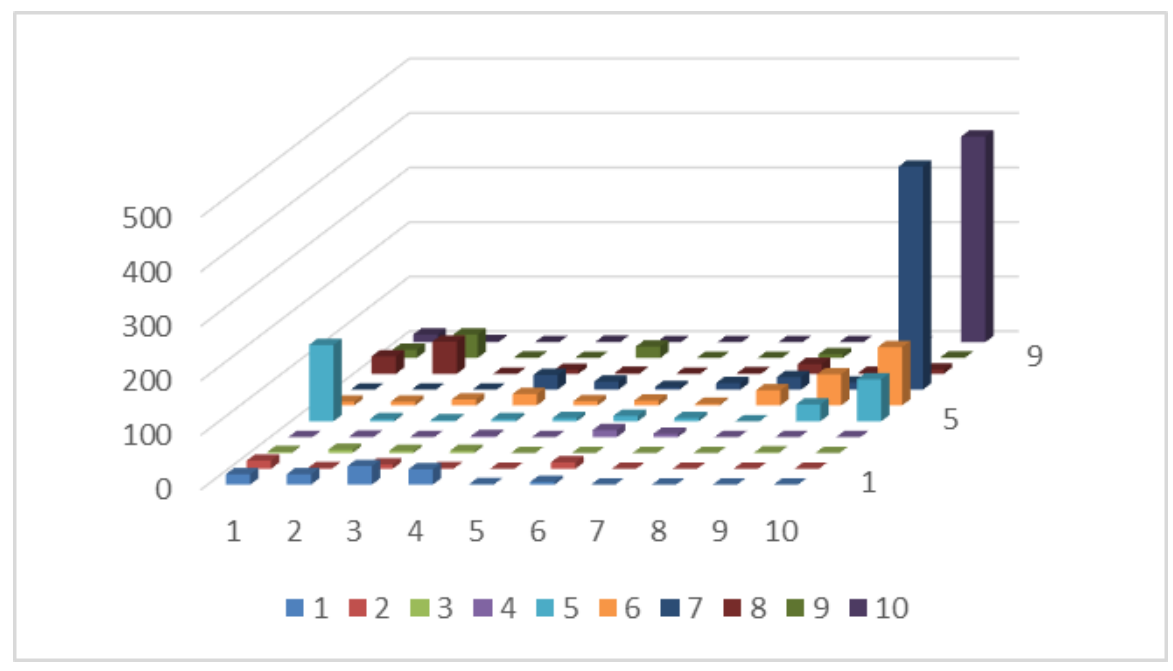

Source: Own production

As previously mentioned, the most populated clusters are Clusters $(7,10)$ and $(10,10)$. Clusters $(5,1),(6,10)$, and $(5,10)$ are worthy of note. The others comprise significantly fewer active companies, while many clusters do not contain any such companies. Similarly, the number of clusters for companies in liquidation will be illustrated (see Figure 2). 
Figure 2: Companies in liquidation in clusters

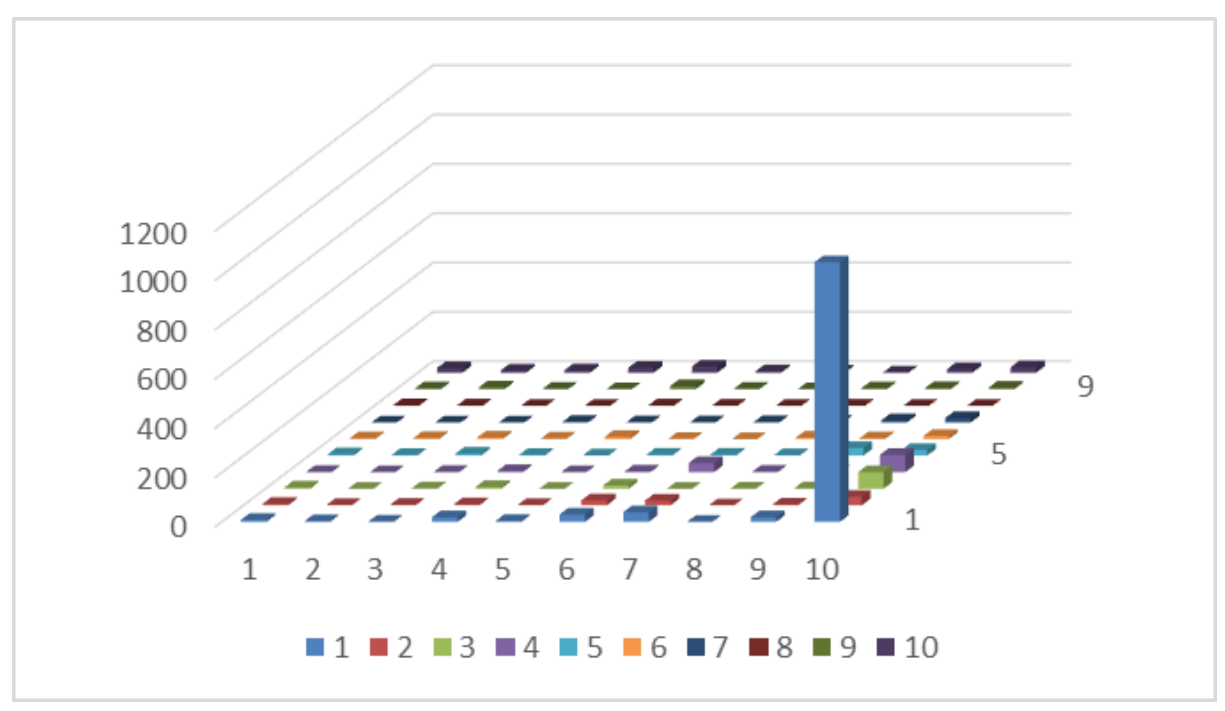

Source: Own production

The figure confirms the dominant position of Cluster $(1,10)$, which clearly contains the most companies of all clusters. All companies in this cluster are in liquidation. Furthermore, Clusters $(3,10)$ and $(4,10)$ are more populated, but include approximately 15 times fewer companies than the largest cluster. These facts again attest to the very good ability of the Kohonen network to classify companies in liquidation.

It is interesting to provide a general description and characteristics of the details of the companies classified by cluster and by status. The sums of the variables are calculated to identify the importance of a cluster for a given industry; the arithmetic mean of the variables then allows us to see what a typical company of a given cluster looks like.

\subsection{Financial Analysis - Clusters $(7,10),(10,10),(8,10)$ Active Enterprises}

In this section, selected clusters of active companies, or the average companies of clusters, are examined.

The average company in Cluster $(10,10)$ has a lower volume of assets, and consequently a higher ROA value; it applies an aggressive financial strategy (higher debt); however, the total cost of interest is fairly low, as is the cost of foreign capital. The companies in $(10,10)$ have a lower volume of personnel costs; they do not have many employees; thus, they perhaps engage subcontractors in their contracts, which implies a higher volume of services in sales. Cluster $(10,10)$ is the most appropriate in terms of financial health. The companies in Cluster $(8,10)$ generate the highest inventory turnover due to their high total inventory, specifically materials.

The companies in Cluster $(10,10)$ are the healthiest financially. The enterprises in Cluster $(7,10)$ have lower profit and loss than those in Clusters $(10,10)$ and $(8,10)$, although they have the highest value of intangible fixed assets, the lowest current liabilities, and the lowest total assets, equity, and sales of in-house services.

The average companies in Clusters $(10,10)$ and $(8,10)$ have similar rates of debt (approximately 60\%); thus, these debt levels can be considered to be the most common for active companies in this sector of the economy.

The current ratio for the average companies in Clusters $(7,10),(10,10)$, and $(8,10)$ always reach the recommended values. The results show that the companies are of sufficiently good financial standing to meet their obligations. The results also show that the current ratios for 
the average companies in all the clusters exceed the given recommendation, i.e. the companies generate a higher quick ratio.

The results show that the cash ratio for the average companies in all three clusters meet the lower bound of the recommended value. The active companies across Clusters $(7,10),(10$, $10)$, and $(8,10)$ generate an asset turnover higher than 1 , which means that, compared to all the enterprises and $50 \%$ of the active companies, these clusters have an ideal and fast asset turnover. By far, the highest asset turnover value is generated by Cluster $(10,10)$.

The best inventory turnover ratio is generated by the average company in Cluster $(10,10)$, where the inventory turnover time is 14 days after rounding, which is a relatively rapid change of inventory into cash or receivables. The turnover time for the enterprises in Cluster $(7,10)$ is four days longer, while the longest time, 22 days after rounding, is seen for enterprises in Cluster $(8,10)$.

Cluster $(7,10)$ has the lowest accounts payable turnover by a factor of 11 . Cluster $(10,10)$ has the highest ratio, while the accounts payable turnover is 17 times after rounding. However, none of the clusters has values close to those for all enterprises, or close to those for $50 \%$ of the active enterprises: they strongly exceed them.

In Cluster $(7,10)$, the companies reach the average (mean value) receivables turnover rate, compared to other clusters of active enterprises. Their turnover rate reaches over 60. Again, the highest turnover was reached, which was over 151 times. Cluster $(8,10)$ has again the lowest turnover rate, hence the longest time. This turnover rate is the closest to the values for all the companies.

The cost of foreign capital is higher for the companies in Cluster $(10,10)$, although those are the most active companies, with a reasonable level of debt (approximately 70\%) and the most expensive foreign financing. Nevertheless, the cost of foreign capital is lower than that of the average company.

The average company in Cluster $(10,10)$ has the lowest asset receivables of the members, i.e. the key persons redeem their receivables against the company, or these receivables do not arise at all - the key persons have no need to draw funds at the expense of the company.

The average company in Cluster $(8,10)$ has the highest ratio of trade accounts receivable to assets; thus, the companies in the cluster do not seem to be able to collect their debts ideally.

All three clusters have similar levels of retained profit / liabilities as both the average company (12.94\%) and the average active company (11.93\%). From this perspective, even the best financial activity does not carry a higher level of retained profit. It can thus be assumed that this profit is paid to members / shareholders as dividends/ shares in profit; thus, among others, the accounts receivable item for the key persons is redeemed.

Loss / liabilities carried forward: Compared to the average $(-8.97 \%)$ and the average active company $(-7.43 \%)$, the average companies in the clusters examined show results that are significantly above the average; however, it is still apparent that the given clusters include companies that show loss carried forward in their accounting.

\subsection{Financial Analysis - Clusters $(3,10),(4,7),(1,10)$ Companies in Liquidation}

The cluster, $(3,10)$, i.e. bankrupt companies, has negative EBIT; therefore, the ratios are also negative. Consequently, it has low total fixed assets and negative accounts receivable for subscribed equity compared to other reference clusters. Cluster $(1,10)$ has the highest level of foreign funds of the reference clusters, $(3,10),(4,7)$, and $(1,10)$, while, similar to other clusters. Cluster $(1,10)$ has negative EBIT, despite quite low interest expenses. Cluster $(4,7)$ 
also has negative EBIT; thus, the ratios are also negative, although it shows positive assets and a lower use of foreign funds.

The clusters of companies in liquidation differ from one another; however, in the case of Clusters $(3,10)$ and $(4,7)$, the absolute EBIT is quite comparable. The profitability ratio, ROS, among the clusters is very high. Cluster $(4,7)$ has approximately 5 times higher sales than Cluster $(3,10)$, which implies that the latter cluster makes more effective use of its financial resources, or has a lower volume of assets. Therefore, it can be concluded that Cluster $(4,7)$ has higher net assets, but makes less effective and lower use of resources. Cluster $(1,10)$ has negative net assets; thus, the total ROA is positive. Cluster $(1,10)$ contains a total of 1,043 companies; the negative net assets of the average company per cluster is due to individual companies with a significantly negative net asset value, with other companies reaching a volume of assets close to positive zero. The negative net asset values are due to the negative values of short-term receivables which seem to have arisen as a result of credit notes issued (i.e. essentially liabilities), or the collection of more 'advances' of payments from clients than were actually invoiced; again, they represent a type of liability that requires the companies to repay the funds thus obtained to the originator. In this respect, the average company in Cluster $(1,10)$ is thus by far the worst and clearly over-indebted.

The negative net debt of the average company in Cluster $(3,10)$ is due to the overall negative foreign capital, which is driven by the negative net liabilities to members / shareholders, i.e. the negative net liabilities to members / shareholders are essentially claims on members / shareholders who, in this case, should ideally return to the firm the funds they have borrowed. The above variable thus changes its original ease of interpretation. Cluster (1, 10) then reaches a positive net debt due to the negative net liabilities (see the negative net assets above) and the negative external resources, again due to the negative net liabilities of members/shareholders. In this respect, the average company in Cluster $(4,7)$ is ironically presented as the best performing company, with a debt ratio of approximately $97.5 \%$, but with positive net liabilities and external resources. It can be extrapolated from the above that the companies in Clusters $(3,10)$ and $(1,10)$ did not receive any support from the key persons who, thus, became debtors of those enterprises.

The average company in Cluster $(4,7)$ is close to the lower limit of the recommended interval, while the other clusters have fairly low liquid assets. Cluster $(3,10)$ has negative current and quick ratios, caused by negative net assets; thus, the indicated ratio loses its original ease of interpretation.

The quick ratio for Cluster $(4,7)$, by the given criterion, is more than successful when it exceeds the recommended liquid assets, i.e. it is more liquid than would be required. Minor differences between the current and quick ratios indicate a low level of assets allocated in inventory, which further corroborates the conclusions that companies in liquidation are trying/are forced to eliminate the amount of funds tied up in inventory. Indeed, the cash position ratio could not be determined because the companies only had a low level or no short-term financial assets.

The asset turnover for the bankruptcy clusters, $(3,10),(4,7)$, and $(1,10)$, did not even reach the minimum values.

For Cluster $(3,10)$, the inventory turnover time for a company is 26 days, while in Cluster $(4,7)$, the turnover time is 58 days; in Cluster $(1,10)$, the turnover time is 2 days, which is an extremely rapid turnover. 
Trade receivables only represent a small part of total assets; for the average company, it was approximately $10.4 \%$, which suggests that companies in liquidation are not very active, although they manage to collect these debts, or conversely, they do not hold any assets.

Companies in liquidation have a higher relative ratio of retained earnings to total liabilities, which can be interpreted to mean that those companies accumulated this source of funding and did not pay it out as shares in profit. Again, therefore, this can be seen as key persons being keen on supporting companies in liquidation and preventing their bankruptcy.

Loss/liabilities carried forward: The ratio supports the predictable conclusion that companies in liquidation have a higher relative volume of losses carried forward relative to liabilities. It is the accumulation of losses carried forward that may force companies to raise additional foreign capital (increasing debt).

\section{Discussion}

The construction sector was deliberately chosen as it plays an important role in any national economy. It employs almost $40 \%$ of the total economically active population in the Czech Republic. It is often referred to as the national economy development indicator, as it can be used to estimate the development of the entire macroeconomic situation; the construction industry would be the first sector exposed to a recession, i.e. a decline in demand, or a boom, i.e. an increase in demand (Linkeschová, 2005). This fact is also mentioned in foreign studies. McGeorge et al. (2013), Vochozka et al. (2015), or Adinoyi and Nor'aini (2015) maintain that the construction industry is the major economic driver in both developed and developing countries.

The calculations and information available make it possible to answer the research questions.

RQ1: Is cluster analysis an appropriate tool for identifying companies that will face bankruptcy?

Yes, Kohonen networks provide a tool that can quite successfully classify businesses into active companies and companies in liquidation. In particular, the group of companies in liquidation was very easily and well identified by the Kohonen networks, based on common characteristics. A vast majority were classified in Cluster (1, 10), which contained 1,053 companies in liquidation, with no active company (i.e. more than $57 \%$ of all the companies in liquidation were included in this single cluster). Another $14 \%$ of the companies in liquidation constituted $100 \%$ representation in some of the other clusters. This means that more than $70 \%$ of companies in liquidation were classified in clusters with $100 \%$ representation of those companies. Therefore, clearly, Kohonen networks can classify companies that will face bankruptcy with high probability.

RQ2: Can businesses be categorised by common characteristics into groups of successful and unsuccessful businesses?

Yes, businesses can be clustered into successful and unsuccessful companies according to their common characteristics. The answer to the first research question already indicated the proportion of companies in liquidation that were fully classified in specific clusters. Considering the situation more closely, a total of 1,443 companies ( $40 \%$ of the total number of enterprises) were classified in the bankruptcy zone, 294 companies (8\% of the total number of enterprises) were classified in the grey zone, and 1,933 companies (52\% of the total number of enterprises) were classified in the creditworthy zone. It is therefore obvious that not all active companies were classified in the active group and, similarly, not all companies in liquidation were classified in the bankruptcy group. Nevertheless, Kohonen networks are 
very successful, and the potential of this type of artificial neural networks to classify businesses by common characteristics into different clusters is hereby confirmed.

RQ3: Can cluster analysis be used to identify key indicators that feature failing businesses?

There is no straightforward answer to this research question. Rather, the answer would be, 'No'. Using cluster analysis, i.e. Kohonen networks, businesses can be highly efficiently clustered into active companies and companies in liquidation based on their subcharacteristics; however, to determine the key indicators that feature bankrupt or active companies, further analysis would be required, mainly financial analysis of the clusters in question, which determines and characterises the key indicators in more detail.

\section{Conclusion}

The aim of this study was to describe, in detail, the issue of business performance and Kohonen networks as a tool used for cluster analysis, and to determine the ability of a business to survive a potential financial distress. To achieve the main objective, three subobjectives that focus on the adjustment of the dataset, the identification of the most successful clusters of companies within the construction industry, and the identification of a specific variable that affects the success of a company, were defined.

First, financial analysis of the underlying dataset was conducted. The results show that companies in liquidation enter into (quite logically) contracts with lower profitability, and that creditors perceive the risks of companies in liquidation that arise from or relate to higher debt levels and require higher returns to cover these risks. Construction companies in the Czech Republic are advised to consider whether they are only using the assets necessary for operation, and to reduce their indebtedness in many cases; additionally, they are advised to strive to increase their business margin, even if this requires offering additional services, and to focus on optimising their financial results (profit and loss).

The items that represent capital structure, such as asset structure, liquid assets, and a company's ability to generate sales and profit, were subject to cluster analysis. Specifically, the following items were considered: total assets, fixed assets, tangible fixed assets, current assets, inventories, long-term receivables, short-term receivables, short-term financial assets, equity, foreign resources, long-term liabilities, short-term liabilities, revenues from sales of goods, revenue from sales of products and services, consumption of energy and materials, services, personnel costs, depreciation of intangible and tangible fixed assets, and interest expenses. Artificial intelligence, i.e. Kohonen networks, was used for the cluster analysis. The results indicated that the companies had negative net short-term receivables, probably arising from credit notes issued or due to the collection of more advances. These businesses did not receive any support from the key persons, who thus became debtors. Companies in liquidation attempt to eliminate the volume of funds tied up in inventories. They do not hold any assets; however, they can reasonably manage to collect trade debts. They can also engage additional foreign capital, increase debt, and accumulate the retained profit - the interest of the key persons in supporting the enterprises and avoiding bankruptcy is apparent.

The aim of the study is thus considered to have been achieved.

The limitations of the research include the fact that data and information from the grey zone, i.e. companies that would face liquidation during the reference period, were not considered. Time and space constraints are another limitation. It would be useful to include a longer time period to compare results over time, as well as to focus on other sectors of the national economy, or possibly other countries, and to compare them. Meanwhile, such future 
research could apply other methods appropriate for cluster analysis or some other econometric methods, including, for example, regression analysis.

Author contributions: All authors listed have made a substantial, direct and intellectual contribution to the work, and approved it for publication.

Funding: This research received no external funding.

Data Availability Statement: Restrictions apply to the availability of these data. Data was obtained from CRIF - Czech Credit Bureau (CRIBIS database) and are available from the authors with the permission of CRIF - Czech Credit Bureau.

Conflicts of Interest: The authors declare no conflict of interest.

\section{References}

Abdou, H., Abdallah, W. M., Mulkeen, J., Ntim, C. G., \& Wang, Y. (2017). Prediction of financial strength ratings using machine learning and conventional techniques. Investment Management and Financial Innovations, 14(4), 194-211.

Adinoyi, Y. M., \& Nor'aini, Y. (2015). Understanding and formalization of innovation: a panacea to inefficiency in construction industry project delivery. 26th International-Business-Information-Management-Association Conference, Spain, 3366-3375.

Andekina, R., \& Rakhmetova, R. (2013). Financial analysis and diagnostics of the company. International Conference on Applied Economics (ICOAE), 5, 50-57.

Barboza, F., Kimura, H., \& Altman, E. (2017). Machine learning models and bankruptcy prediction. Expert Systems with Applications, 83, 405-417.

Gupta, R., Mejia, C., Gianchandani, Y., \& Kajikawa, Y. (2020). Analysis on formation of emerging business ecosystems from deals activities of global electric vehicles hub firms. Energy Policy, 145.

Halim, Z., Shuhidan, S. M., \& Sanusi, Z. M. (2021). Corporation financial distress prediction with deep learning: analysis of public listed companies in Malaysia. Business Process Management Journal, 27(4), 1163-1178.

Kenny, G. (2012). From the stakeholder viewpoint: Designing measurable objectives. Journal of Business Strategy, 33(6), 40-46.

Le, T. M., Wang, C. N., \& Nguyen, H. K. (2020). Using the optimization algorithm to evaluate and predict the business performance of logistics companies - A case study in Vietnam. Applied Economics, 52(38), 41964212.

Lehtinen, J. R. (2007). Aktivni CRM: Řizeni vztahů se zákazníky [Active CRM: Customer relationship management]. Grada Publishing.

Linkeschová, D. (2005). K otázkám managementu ve stavebnictví [On issues of management in construction]. Akademické nakladatelství [Academic publishing house] CERM.

Linna, P., \& Jaakkola, H. (2010). Toward finding culture assessment tools for SE companies. Portland International Center for Management of Engineering and Technology (PICMET 10).

Malichová, E., Ďurišová, M., \& Tokarčíková, E. (2017). Models of application economic value added in automotive company. Transport Problems, 12(3), 93-102.

Mcgeorge, D., Zou, P., \& Palmer, A. (2013). Construction management: New directions. John Willey \& Sons, Ltd.

Narkuniene, J., \& Ulbinaite, A. (2018). Comparative analysis of company performance evaluation methods. Entrepreneurship and Sustainability Issues, 6(1), 125-138.

Nenadál, J., Vykydal, J., \& Halfarová, P. (2011). Benchmarking: Mýty a skutečnost: model efektivního učení se a zlepšování [Benchmarking: myths and reality: A model of effective learning and improvement]. Management Press.

Nirino, N., Santoro, G., Miglietta, N., \& Quaglia, R. (2021). Corporate controversies and company's financial performance: exploring the moderating role of ESG practices. Technological Forecasting and Social Change, 162. 
Sovacool, B. K., Noel, L., \& Orsato, R. J. (2017). Stretching, embeddedness, and scripts in a sociotechnical transition: explaining the failure of electric mobility at Better Place (2007-2013). Technological Forecasting and Social Change, 123, 24-34.

Uthayakumar, J., Metawa, N., Shankar, K., \& Lakshmanaprabu, S. K. (2020). Financial crisis prediction model using ant colony optimization. International Journal of Information Management, 50, 538-556.

Verma, S., \& Gustafsson, A. (2020). Investigating the emerging COVID-19 research trends in the field of business and management: a bibliometric analysis approach. Journal of Business Research, 118, 253-261.

Vochozka, M., Rowland, Z., \& Vrbka, J. (2015). Evaluation of credibility of civil construction companies in South Bohemia. Innovative Economic Symposium 2015, Czech Republic, 145-161. 